\section{TOPOLOGICAL OPTIMIZATION OF THE FORMULA STUDENT BELL CRANK}

\author{
JAKUB MESICEK, MAREK PAGAC, JANA PETRU, PETR NOVAK, \\ JIRI HAJNYS, KRISTYNA KUTIOVA \\ Faculty of Mechanical Engineering, VSB - Technical University \\ of Ostrava, Ostrava, Czech Republic \\ DOI: 10.17973/MMSJ.2019_10_201893 \\ jakub.mesicek@vsb.cz
}

This paper focuses on the topological optimization of the Formula Student bell crank. Modern trends in designing are weight reduction, and due to this, also reduction of fuel consumption. Topological optimization allows modification of the shape of the component in respect to the strength demand and the boundary conditions of component loading.

The topological optimization software with respect to computational methods is used. This software accomplishes several interactions and evaluates the optimal one. Topologically optimized component manufacturing is usually done by 3D printing. In this article, the authors follow the development of a topologically optimized bell crank, choice of printing material (metallic powder), and description of its design development and geometrical shape smoothing step by step - from the very first design to the final topologically optimized model. The design also takes into consideration the production technology by metallic powder 3D printing and post-processing, which cannot be realized without CNC machining and clamping jigs.

KEYWORDS

topological optimization, bell crank, suspension, 3d printing, metallic powder.

\section{Introduction}

Formula Student is an international student engineering competition, and its aim is to build and compare designs of formula racing cars. Students from technical universities design, build and test their formula type vehicles and then race with them at prestigious international competitions. Competition comprises static and dynamic disciplines. In each part of these disciplines, the aim is to get as many points as possible. Each discipline is rated by a different number of points, depending on the discipline's importance. Overall point score determines the winner.

Precise wheel guiding on the track is very important if we speak about racing vehicles. That is the reason why teams usually choose stiff suspension. Each suspension part deformation must not participate in wheel stroke damping due to applying precise settings. Low weight is also pivotal for racing cars, which is why engineers still innovate every single part by new technologies and software, like topological optimization and bionic design.

Topological optimization leads to a pushing down of the defined solid's volume. The main process, which applies specialized software, is based on taking material volume away at less loaded areas. From this procedure the model is made, where only part of the material is functional with reduced volume. Final model shapes are usually very complicated, which is a problem during manufacturing by conventional methods. One solution to this problem is by using additive manufacturing, which allows manufacture of real parts by 3D printing. [Beniak 2015]

The bell crank (Fig. 1) is a component for transferring forces and moves. It works on the principle of the lever. It is part of the suspension of many chassis types and usually constitutes the pivoting connecting of damper, suspension and link. Due to the easy use of this component, it is possible to optimize mass or increase the stiffness. The model for optimization is original steel bell cranks manufactured by conventional machines (Figure 1 , left).

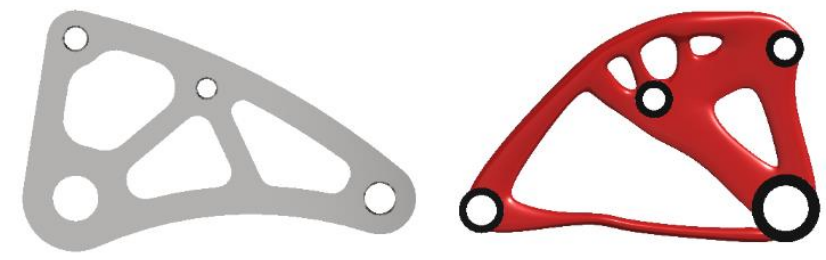

Figure 1. Original (left) and optimized bell crank (right)

\section{Topological optimization}

\subsection{Principle of topological optimization}

The principle of topological optimization can be explained by way of the beam example (Fig. 2), where we want to determine the supportive structure needed to support a homogeneously distributed load on the surface. As figure 2 shows, in the lower part there are three fixed supports. [Eschenauer 2001], [Bendsoe 2003]
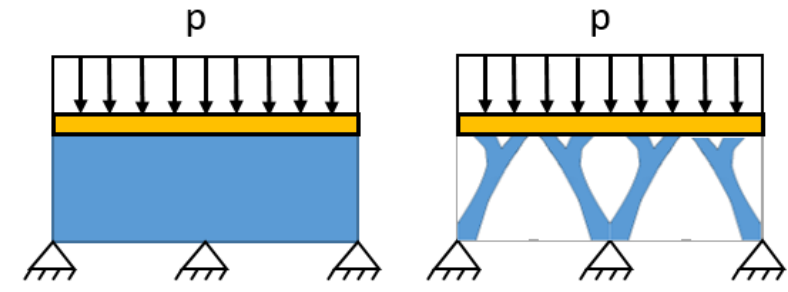

Figure 2. Prerequisite of optimization explained by beam example

Using topological optimization, we made a model of this structure as a beam loaded with a homogeneous distributed load on its surface. Three fixed supports, one at each side and one in the middle of the beam, are used. The lower outcome (Fig. 3) corresponds to publicated solution. The generated shape is a bridge deck on two supportive vaults, which transfer pressure load onto fixed supports. This model needs to be smoothed to continual surface mesh. Also, in the case of metallic 3D printing, take into consideration manufacturing, which includes the design of supportive material and additional material to areas where precise manufacturing is expected.

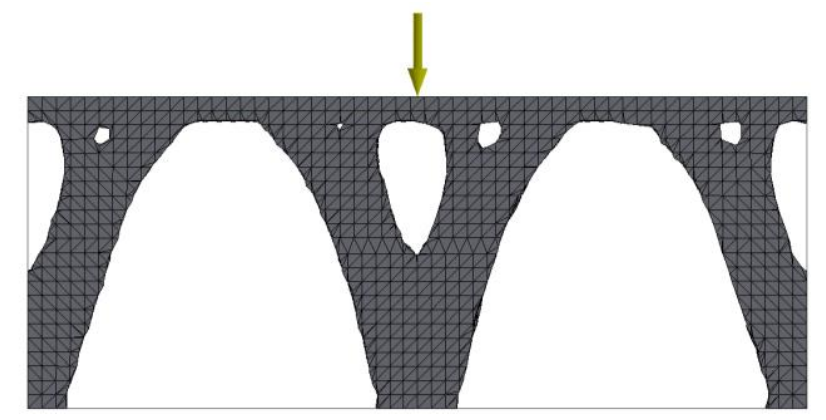

Figure 3. Optimized beam

It is possible to use many software applications for topological optimization. Some of them are available for free, and in case of manufacturing purposes, commercial software exists. Perhaps some well known examples of software are: 
- Abaqus

- Altair

- Ansys

- Femap

- Genesis

- MSC Nastran

- OptiStruct

- Protop

- Simulia (Tosca Structure)

- SolidThinking Inspire

\subsection{Topology Optimization Formulation}

An isotropic element's consistent mass matrix is:

$\left[m_{e}\right]=\rho_{e} \int_{V_{e}} \quad\left[N_{e}\right]^{\tau}\left[N_{e}\right] d V$

where:

$\rho_{e}$ - the element density, $V_{e}$ - the element volume, and $\left[\mathrm{N}_{\mathrm{e}}\right]$ - the interpolation function matrix for each element. [EARMME 2009] Accordingly, this total structural mass matrix could be written as:

$\left[m_{e}\right]=\sum_{e=1}^{n_{e}} \quad\left[m_{e}\right]$

This equation shows that by changing the element density, we can change also the mass of the structure.

In this example, the optimization criterion is the norm of the difference between initial structure and objective structure. In other topology optimization techniques, minimization of compliance is usually used. This allows the designer to obtain a structure which satisfies multiple performance objectives, as well as material specifications. [EARMME 2009]

\section{Topological optimization of the vector 04 bell crank}

The topological calculation itself was performed in the SolidThinking Inspire software. [Solidthinking 2019]

\subsection{Inputs}

For topological optimization, the bell crank of the third prototype formula car, called Vector 03, was chosen (Fig. 4). This bell crank was made of steel, by conventional methods of manufacturing. It is comprised of three parts - two shields cut by laser beam, and a tube. These parts were welded together and then precise holes were machined into its attachment on the formula's frame.

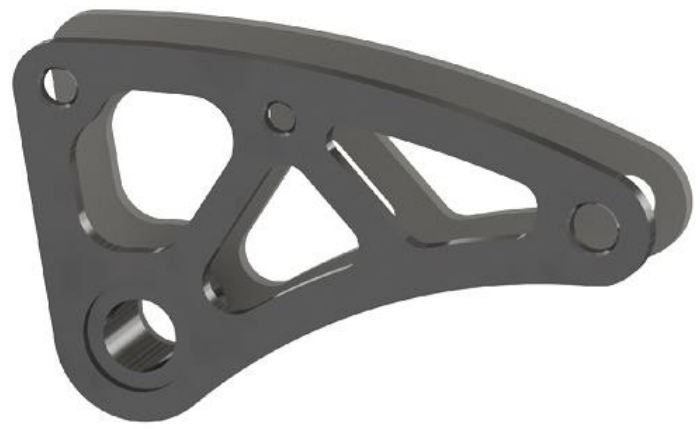

Figure 4. The Original Bell Crank
Topological optimization draws on the so called Design Area (Fig. 5), which is the model of maximal allowed volume of the component given by assembling area - area can be defined as maximum allowed solution.

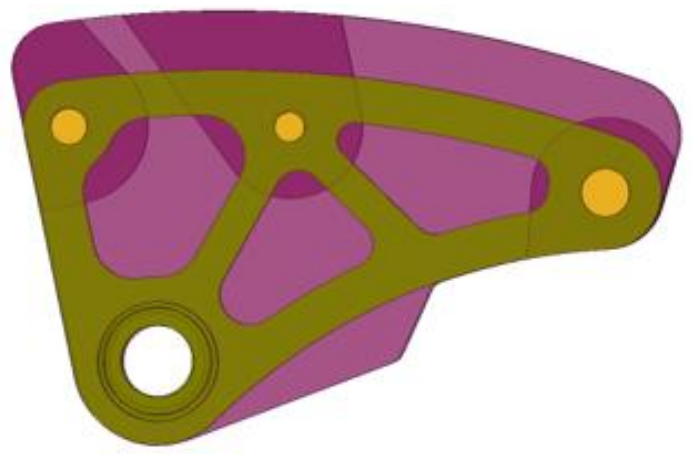

Figure 5. Design Area, purple area is maximal allowed area of model

To determine the areas that should be maintained during the computation (material that cannot be removed), it is important to define their connection to other components. In the case of bell cranks, this concerns rounded holes for pins (Fig. 6).

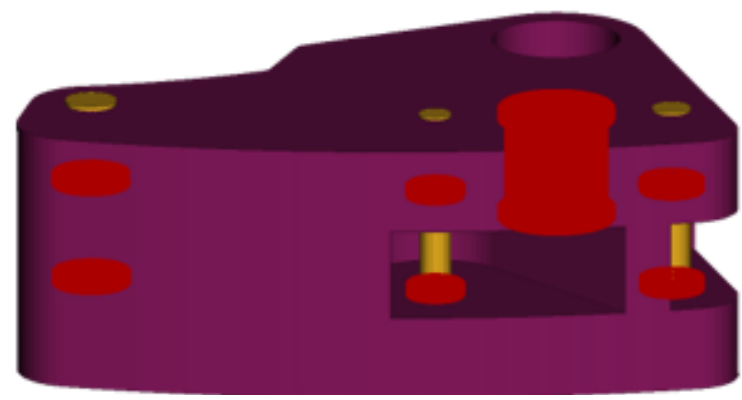

Figure 6. Frozen area

In considering the use of metallic powder, which are available for Selective Laser Melting 3D printing technology, Inconel 718 nickel steel was chosen. Inconel 718 has high breaking strength (>>1000 MPa), and its material properties are appropriate for the component's function. [Xia 2017] Higher strength allows a decreasing of the component mass - that is one of the targets of topological optimization. When the material was chosen, boundary conditions needed to be defined. Boundary conditions were defined on the basis of forces ratio, torque moments and their distribution, that load bell cranks from other formula components and frames. Resolution of forces is shown in figure 7.

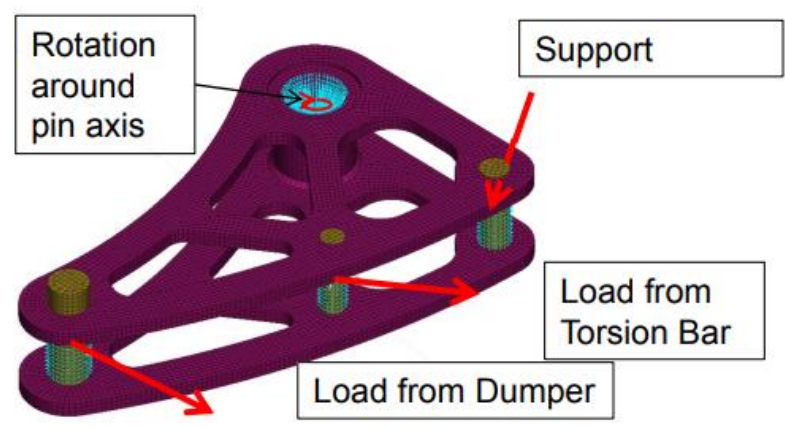

Figure 7. Bell crank loads

During the simulation and resolution of forces, it was discovered that the force from the suspension part is $4000 \mathrm{~N}$ and force from 
the anti roll bar is $2412 \mathrm{~N}$. Loading is based on suspension assembly dynamic analysis depending on riding conditions. In figure 8, the setting of optimization criteria is shown. The type of optimization chosen was Topology. Topological optimization allows computation, its target being to maximize stiffness or minimize mass.

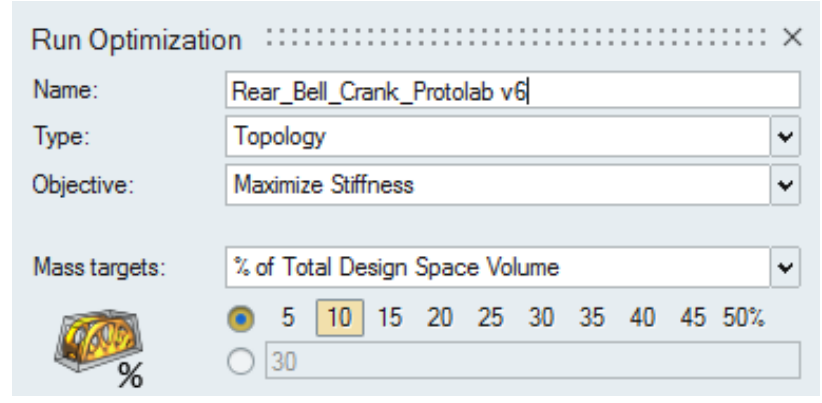

Figure 8. Optimization setup

The primary target of optimization was to increase component stiffness, that is why the method of maximizing stiffness was chosen. The mass target was $10 \%$ of the original design area volume. This setting seemed like the best in comparison with nearly thirty different interactions. Minimal thickness of the wall was $3.875 \mathrm{~mm}$, and contacts were determined like Sliding only.

\subsection{Outputs}

After several interactions, where the correct settings of optimization criteria were detected, is output in figure 9. This output structure's shapes do not give the impression of technical shapes; rather, it resembles a biological structure. [Yan 2019]

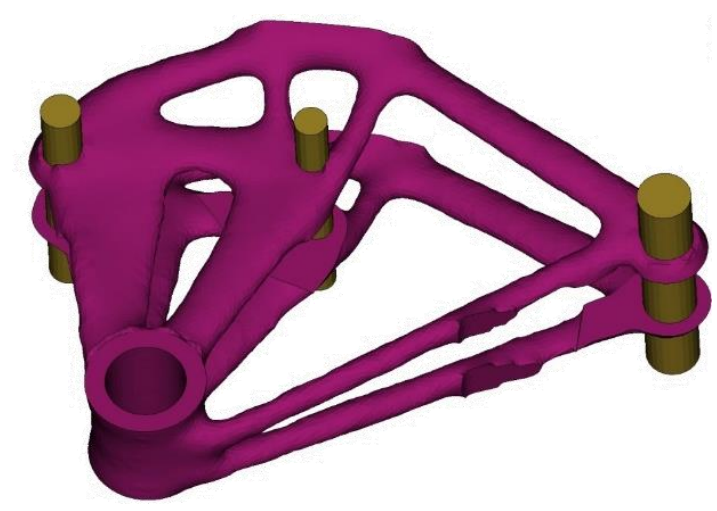

Figure 9. Generated structure

A topologically optimized generated model is possible to manufacture by 3D printing. But before data sending, it is usual for the final surface to be smooth and each part of it, which are created on the basis of computation, should be tangentially connected to each other. Sharp areas and transitions can cause peaks of yield stress and could be a source of deformations and destruction. Surface smoothing is done by CAD software tools and is then verified by stiffness analysis if the component is genuinely resistant, complies with boundary conditions and does not show yield stress peaks. The bell crank model is adjusted by the Polynurbs function in this case. The optimized bell crank (Fig. 10) has tangentially rounded shapes, and due to this, there was a reduced number of yield stress concentrators.

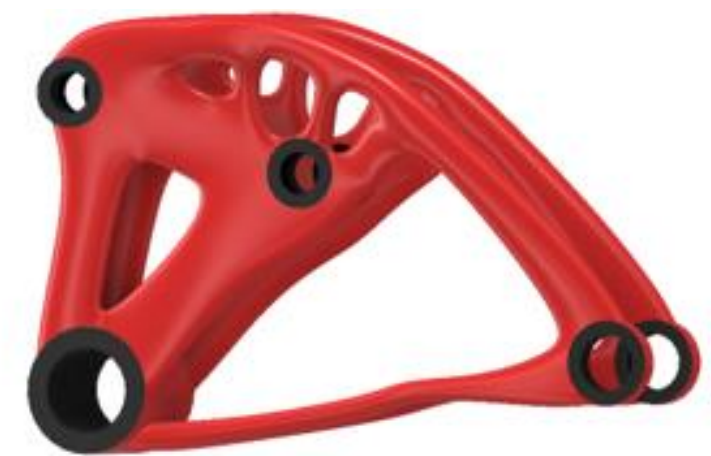

Figure 10. Final design of the Bell Crank

In figure 11 is the assembly of the optimized bell crank in the Formula Student's suspension. This bell crank is mounted in sliding teflon cases on a precise pivot, which is mounted on a steel tubular frame of the vehicle. Then there are screw connections with a damping part, anti roll bar links and suspension.

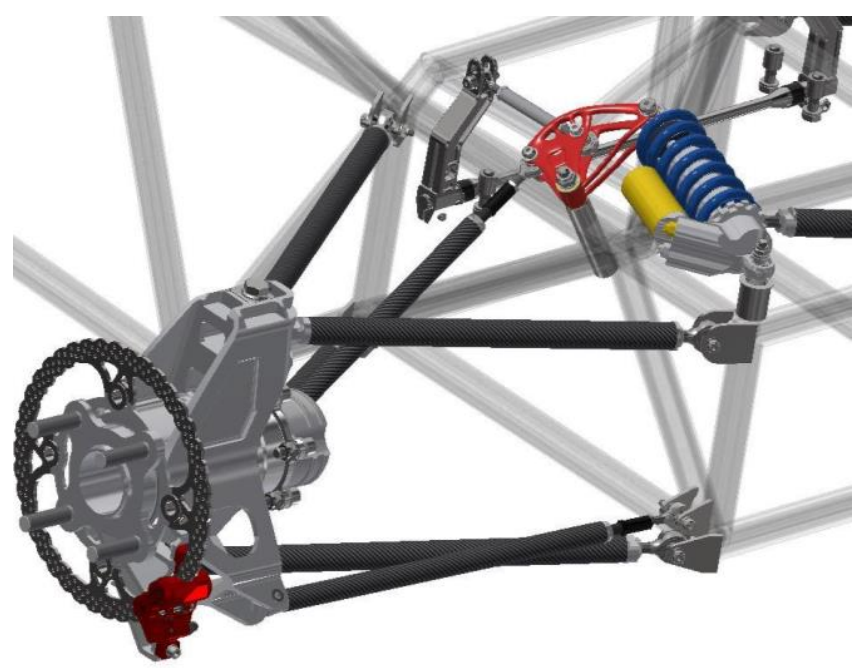

Figure 11. The Bell Crank in assembly

\section{Comparison}

To compare the properties of the original and optimized bell cranks, a stress analysis was made. Maximal stress (type Equivalent Stress) in the original bell crank during static FEM analysis was $650.5 \mathrm{MPa}$. The highest stress was in the shield area, which creates a stress concentrator (Fig. 12).

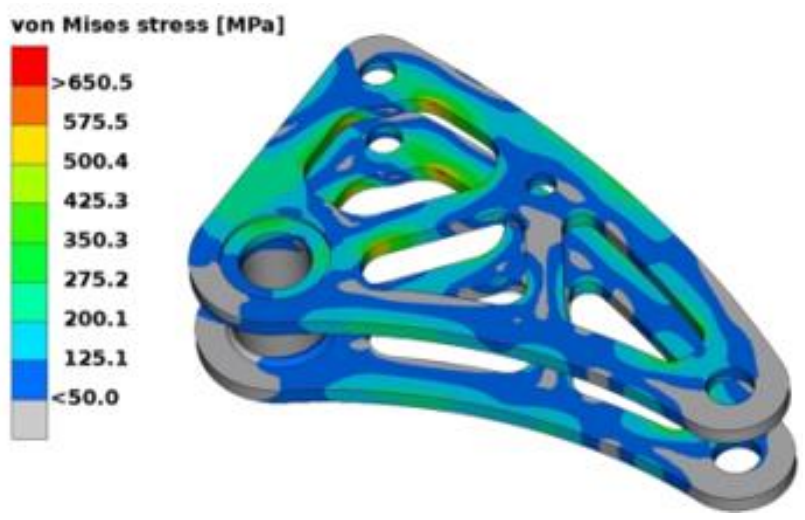

Figure 12. Yield stress of The Original Bell Crank

Maximal yield stress (type Equivalent Stress) in the optimized bell crank during static FEM analysis was $381.5 \mathrm{MPa}$, which is much less than the yield strength of the chosen material. Yield stress in the bell crank is shown in figure 13. 


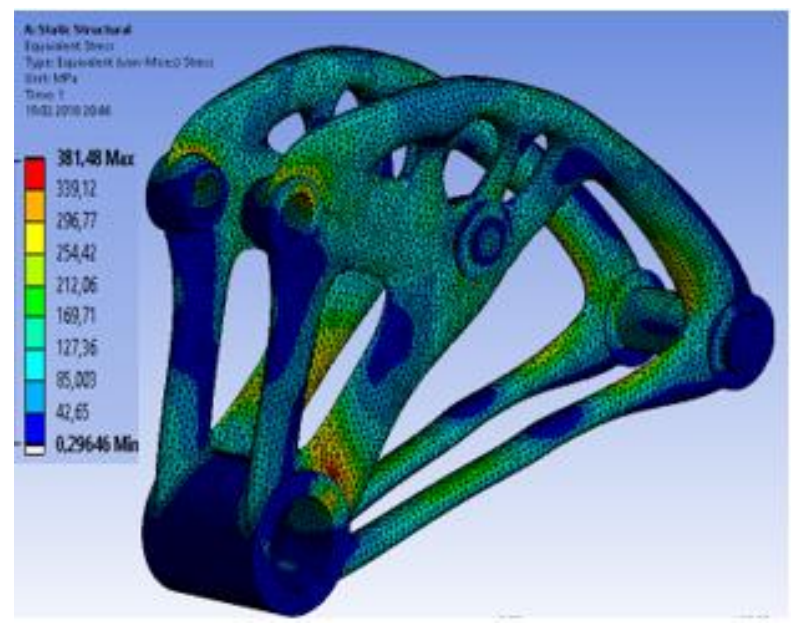

Figure 13. Yield stress of the final design of The Bell Crank

Values of maximal yield stress in the optimized bell crank are 43 $\%$ less than in the original bell crank. This contrast is shown by the diagram in figure 14. This comparison of the original and optimized bell cranks is evidence we can decrease this yield stress only by changing the shape of this component.

\section{Compare of maximum yield stress}

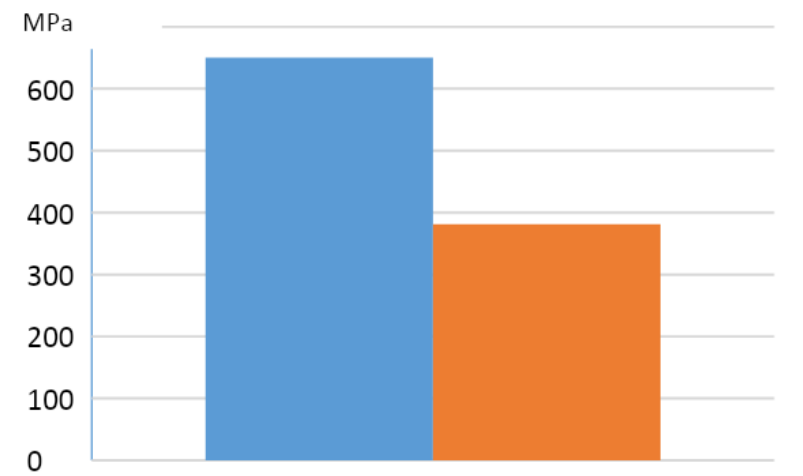

ORIGINAL BELL CRANK, — OPTIMIZED BELL CRANK

Figure 14. Comparison of maximum yield stress

Stiffness increased by $32 \%$, and also mass was decreased by $7 \%$ in topological optimization of the bell crank. It was accomplished by a change of material from original steel to Inconel 718 . Comparison is summarized in tab 1.

\begin{tabular}{|c|c|c|c|c|c|c|}
\hline PROPERTIES & 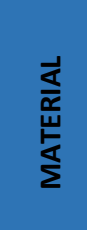 & $\stackrel{n}{\Sigma}$ & 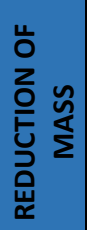 & 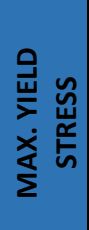 & 选 & 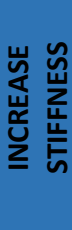 \\
\hline $\begin{array}{l}\text { ORIGINAL } \\
\text { BELL CRANK }\end{array}$ & $\begin{array}{c}\text { Docol } \\
700\end{array}$ & $134 \mathrm{~g}$ & - & $\begin{array}{l}650 \\
\mathrm{MPa}\end{array}$ & $\begin{array}{l}0.25 \\
\mathrm{~mm}\end{array}$ & - \\
\hline $\begin{array}{l}\text { OPTIMIZED } \\
\text { BELL CRANK }\end{array}$ & $\begin{array}{c}\text { INCO } \\
\text { NEL } \\
718\end{array}$ & $125 \mathrm{~g}$ & $7 \%$ & $\begin{array}{l}381 \\
\mathrm{MPa}\end{array}$ & $\begin{array}{l}0.17 \\
\mathrm{~mm}\end{array}$ & $32 \%$ \\
\hline
\end{tabular}

Table 1. Comparison of a topologically optimized bell crank with original

\subsection{Consideration of the possibility of material change}

Another alternative of materials appropriate for 3D printing of bell cranks are titanium alloy, stainless steel and aluminium alloy (tab. 2). [Hajnys 2018] In table 2, masses of bell cranks are shown which were manufactured by 3D printing using these materials. [Martin 2017]

\begin{tabular}{|c|c|c|c|c|}
\hline Figure material & AISI 316L & AlSi10Mg & Ti6Al4V & $\ln 718$ \\
\hline Mass [g] & 122 & 40.8 & 67.3 & 124.7 \\
\hline Density $\left[\mathrm{kg} \cdot \mathrm{m}^{-3}\right]$ & 8000 & 2680 & 4420 & 8190 \\
\hline $\begin{array}{l}\text { Yield strength } \\
\text { [MPa] }\end{array}$ & 518 & 266 & 988 & 1088 \\
\hline
\end{tabular}

Table 2. Comparison of the mass of a topologically optimized bell crank in contrast to the metallic powder used

\section{Manufacturing}

The bell crank was made using 3D SLM printing (selective laser melting). Printing was performed on an EOS M 300. Print data was prepared using a combination of Materialize Magics and Autodesk NetFabb. The bell crank is printed from Inconel 718 nickel alloy powder and a layer thickness of $50 \mu \mathrm{m}$ is used. The orientation of the bell crank in the building chamber was chosen with a view to minimizing the supports and positioning them in well removable locations. Bell crank with supports attached to the building board immediately after being pulled out of the machine's construction chamber (Fig. 15).

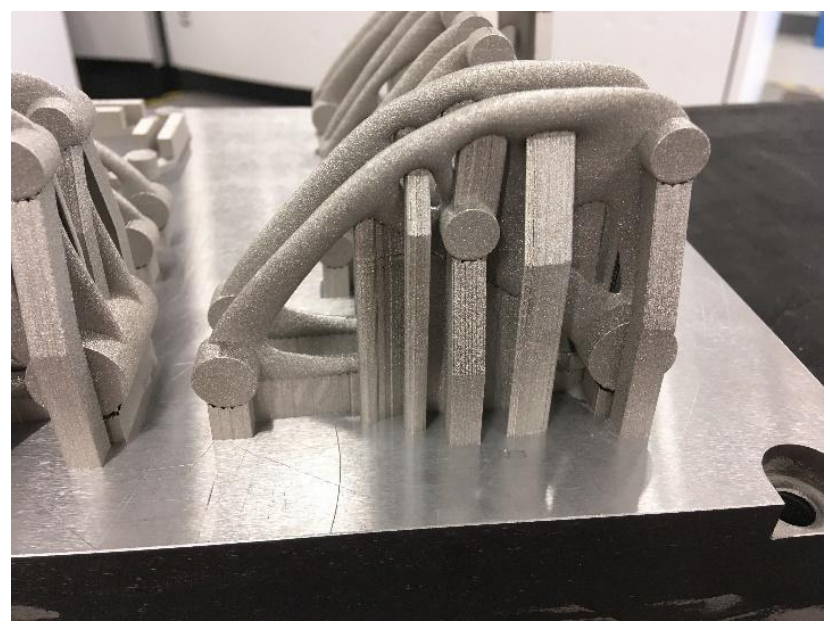

Figure 15. Bell crank attached to a building board

\section{6 conclusion}

Topological optimization opens new access to designers and technologists in designing components where decreasing mass is demanded with maintenance of stiffness properties. Within the student project, topological optimization of the bell crank was realized with the target of increasing the stiffness. Topological optimization was achieved by computational software, and from several interactions output was chosen. This output mass was $7 \%$ less than in the original bell crank, as well as a maximal value of yield stress which was $43 \%$ less ( $381 \mathrm{MPa}$ ) 
than shown in the original bell crank. Another advantage is spacing insert integration, because their mounting was very difficult. The resulting topologically optimized bell crank mounted in Formula Student Vector 04 is shown in Figure 16.

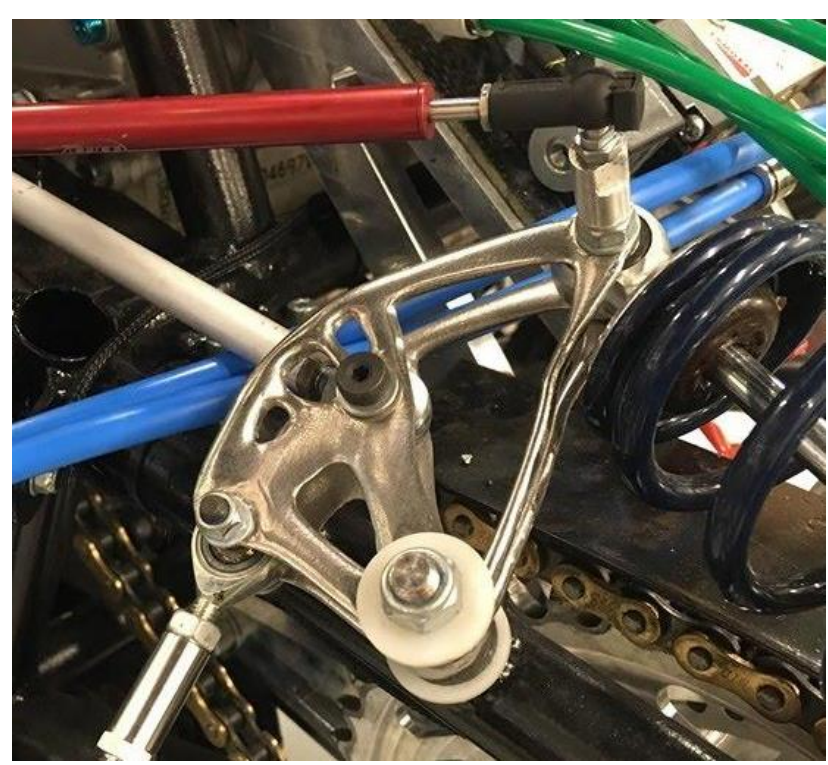

Figure 16. Bell crank in the car

Considering the possibilities of metallic 3D printing and the design possibilities of additive manufacturing, we will dedicate the topological optimization of bell cranks designed as miniature

[Bendsoe 2003] M. P. Bendsoe and O. Sigmund, Topology Optimization: Theory, Methods and Applications Berlin: Springler-Verlag, 2003. ISBN: 3-540-429921

[Beniak 2015] BENIAK, Juraj A comparison of the tensile strength of plastic parts produced by a fused deposition modeling device. In Acta Polytechnica. Vol. 55, no. 6 (2015), s. 359-365. ISSN 1210-2709

[Duda 2016], Duda T., L. Venkat Raghavan. 3D Metal Printing Technology: Proceedings of 17th IFAC Conference on International Stability, Technology and Culture TECIS 2016: Durrës, Albania, 26-28 October 2016, IFAC-PapersOnLine, Volume 49, Issue 29, 2016, Pages 103-110, DOI: 10.1016/j.ifacol.2016.11.111, ISSN: 24058963

[EARMME 2009] EARMME, Taemin. Evolutionary structural optimization with multiple performance constraints by large admissible. Michigan: The University of Michigan. 2009.

[Eschenauer 2001] Eschenauer, HA \& Olhoff, N 2001, 'Topology Optimization of Continuum Structures: A Review' Applied Mechanics Review, Vol. 54, pp 331-390.

[Hajnys 2018] Hajnys, J. et al. Stiffness of 316L stainless steel support structures proposed for the SLM process. 3rd International Scientific Conference on Innovative Technologies in Engineering Production (ITEP), Bojnice, Slovakia, France: EDP Sciences, Article Number: 01008

[Martin 2017] Martin, J. H. et al. 3D printing of high-strength aluminium alloys. Nature. Vol. 549, pp 365, ISSUE: 7672 ISSN: 0028-0836 lattice structures, which leads to even higher mass decreasing (Fig. 17). [Vyatskikh 2018]

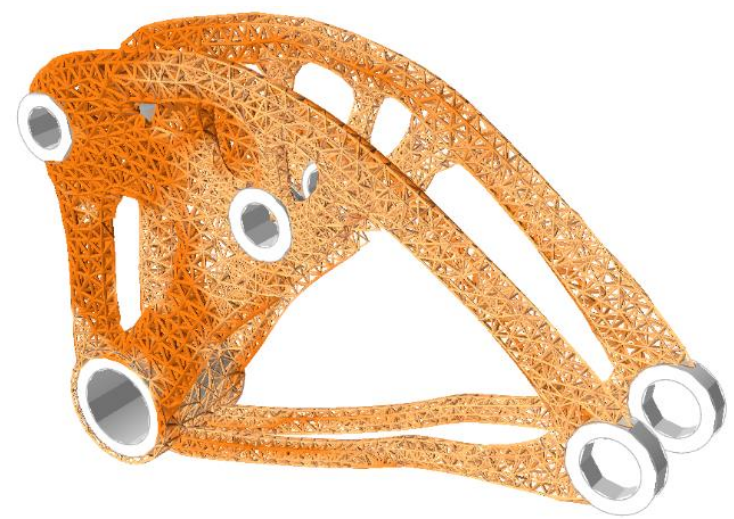

Figure 17. Bell crank designed as lattice structure

\section{Acknowledgments}

This article has been completed in connection with project Innovative and additive manufacturing technology - new technological solutions for 3D printing of metals and composite materials, reg. no. CZ.02.1.01/0.0/0.0/17_049/0008407 financed by Structural Funds of European Union and project.

This article has been elaborated in the research project Research Centre of Advanced Mechatronic Systems, reg. no. CZ.02.1.01/0.0/0.0/ 16_019/0000867 in the frame of the Operational Program Research, Development and Education.

\section{References}

[Solidthinking 2019] SolidThinking, Inc. solidThinking Inspire 2017.2. [online]. 16.3.2017 [11.7.2019]. Available from:

<https://solidthinking.com/help/Inspire/2017.2/ win/en_us/index.html?welcome.htm>

[Vyatskikh 2018] Vyatskikh, Et al. Additive manufacturing of 3D nano-architected metals. NATURE COMMUNICATIONS, February 2018, Vol. 9, Article Number: 593

[Xia 2017] Xia, M. et al. Porosity evolution and its thermodynamic mechanism of randomly packed powder-bed during selective laser melting of Inconel 718 alloy. INTERNATIONAL JOURNAL OF MACHINE TOOLS \& MANUFACTURE. Vol. 116, pp 96-106. ISSN: 0890-6955

[Yan 2019] Yan, SN., Et al. Bionic design and verification of high-precision machine tool structures. INTERNATIONAL JOURNAL OF ADVANCED MANUFACTURING TECHNOLOGY, October 2015, Vol. 81, No.1-4., pp 73-85. ISSN: 0268-3768

\section{CONTACTS:}

Ing. Jakub Mesicek

VSB-Technical University of Ostrava, Department of Machining, Assembly and Engineering Metrology

17. listopadu 15/2172, Ostrava - Poruba, 708 33, Czech Republic

+420 597324 531, jakub.mesicek@vsb.cz, www.fs.vsb.cz 